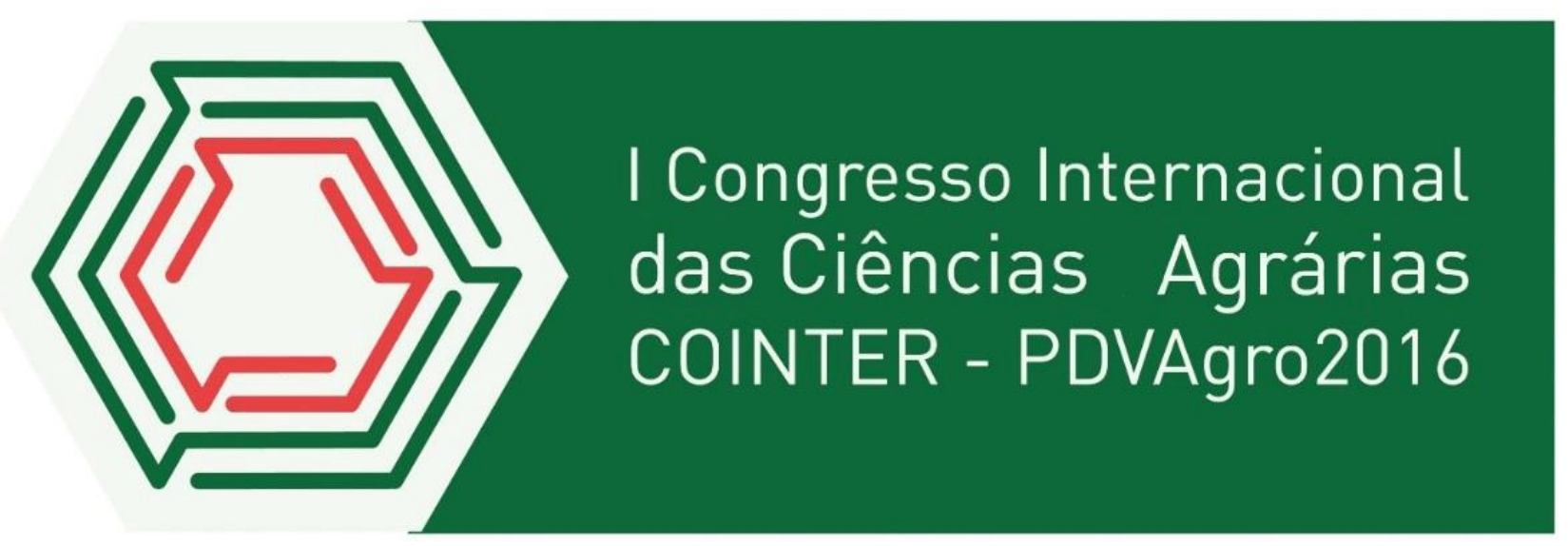

\title{
INFLUENCIA DO TAMANHO E UMEDECIMENTO DE SEMENTES DE RICINUS COMMUNIS NO PROCESSO GERMINATIVO
}

\author{
Apresentação: Pôster \\ Anderson Lucas da Silva ${ }^{1}$; José Denílson da silva ${ }^{2}$; Cláudio Correia dos Santos ${ }^{3}$; Pablo Radamés \\ Cabral de França ${ }^{4}$
}

\section{Introdução}

A mamona (Ricinus communis L.) é uma espécie de clima tropical, com resistência à seca e grande necessidade em calor e insolação (BIZINOTO et al., 2010), de origem incerta, pois existem afirmações de seu cultivo nos continentes asiático e africano (CANGEMI et al., 2010). A demanda por sementes de mamona vem sofrendo um aumento devido à importância econômica de suas sementes muito utilizadas como fonte de matéria-prima para a fabricação do biodiesel. Porém, um dos desafios para a produção desse combustível alternativo tem sido a produção de sementes em quantidade e qualidade para atender o crescente mercado dessa cultura e que possam ser uma alternativa de desenvolvimento, principalmente para a região Nordeste (FRANÇA et al., 2016). Assim, torna-se de fundamental importância o alcance das melhores características produtivas, evidenciando desta forma a importância da padronização e qualidade fisiológica destas. Segundo Zuchi et al. (2010) a mamona apresenta grande variação no tamanho das sementes estando relacionado com a variabilidade genética e a ordem de maturação dos frutos.

O estudo da influência do tamanho da semente é de extrema importância para a padronização da germinação, bem como o desenvolvimento uniforme das plântulas e consequente amadurecimento dos frutos. Segundo Carvalho \& Nakagawa (2000), a quantidade de água para reidratação dos tecidos depende do tamanho das sementes, embora essas afirmações sejam rebatidas

\footnotetext{
${ }^{1}$ Curso Bacharelado em agronomia, IFPE, andersonagro1@ hotmail.com

${ }^{2}$ Curso Bacharelado em agronomia, IFPE, denisonsila@gmail.com

${ }^{3}$ Curso Técnico de Zootecnia, IFPE, claudiocorreia555@gmail.com

${ }^{4}$ Dr. Pesquisador DCR FACEPE/CNPq, IFPE, pabloradames@ hotmail.com
} 
por outros autores que comprovaram que o tamanho da semente não influencia o processo de germinação, indicando que essa associação entre tamanho da semente e tempo de absorção e de entrada no processo germinativo varia em intensidade de acordo com a espécie.

Objetivou-se com este trabalho avaliar o potencial fisiológico de sementes de $R$. communis em relação ao seu tamanho e à quantidade de água utilizada no substrato para umedecimento.

\section{Fundamentação Teórica}

O estabelecimento da plântula depende de diversos fatores internos à semente, como conteúdo de reserva, teor de água, dentre outros e externos a esta como as condições ambientais. Sendo que para alguns autores a qualidade fisiológica das sementes é proporcional ao seu tamanho, isto é, sementes maiores apresentam maiores valores de germinação e crescimento inicial de plântulas (GASPAR e NAKAGAWA, 2002), afirmações estas que contradizem com estudos realizados por (ZUCHI, et al., 2012), que analisou a qualidade fisiológica de sementes de mamona de diversas variedades classificadas por tamanho, onde sementes menores obtiveram os maiores valores na velocidade de germinação.

Quanto maior o tamanho da semente, consequentemente maior o seu conteúdo de reserva e maior a necessidade de água requerida pela semente para hidratação dos tecidos para sua germinação, assim a disponibilidade de água é o fator de maior influência a se observar, pois sua entrada na semente favorece a reidratação dos tecidos e intensifica atividades metabólicas que culminam com o fornecimento de energia e junto com o aumento do volume da semente resulta na germinação (CARVALHO e NAKAGAWA, 2000).

Os estudos de (ZUCHI et al., 2012) corroboram com as afirmações dos autores anteriormente citados, que estudaram a curva de embebição e condutividade elétrica de sementes de mamona classificadas por tamanho, verificando que sementes classificadas em maior tamanho e espessura, apresentaram maior absorção de água.

\section{Metodologia}

O experimento foi realizado no Laboratório de Sementes do Instituto Federal de Pernambuco, Campus Vitória de Santo Antão, sendo utilizadas sementes de $R$. communis cultivar 
BRS Energia, as quais foram classificadas com auxílio de um paquímetro digital em dois tamanhos; TM1- sementes até 10,9 mm e TM2- sementes maiores que 14,0 mm. Em seguida as sementes foram acondicionadas em rolos de papel os quais foram umedecidos com 2,0; 2,5; 3,0 e 3,5 vezes o peso do substrato seco em mililitros de água sem adição posterior e colocadas para germinar em germinador tipo B.O.D (Biochemical Origem Demand) regulado à temperatura de $30{ }^{\circ} \mathrm{C}$ e fotoperíodo de 12 horas, utilizando lâmpadas fluorescentes tipo luz do dia (4x20 W). As contagens foram realizadas considerando como germinadas as sementes que emitiram a raiz primária. Além da germinação foi avaliado o vigor através dos seguintes testes:

Primeira contagem de germinação: conduzida conjuntamente ao teste de germinação e correspondeu à porcentagem de plântulas germinadas ao sétimo dia após o início do teste.

Índice de velocidade de germinação (IVG): avaliado conjuntamente com o teste de germinação, no qual foram realizadas contagens diárias, do sétimo até o $11^{\circ}$ dia após a semeadura.

Comprimento de plântulas: ao final do teste de germinação para determinação do crescimento das plântulas de cada repetição, foram medidas com auxilio de uma régua graduada em centímetros sendo o resultado expresso em cm/plântulas.

Massa seca: para determinação do desenvolvimento, as plântulas foram colocadas por repetição em sacos de papel e levados à estufa regulada a $65^{\circ} \mathrm{C}$ durante 24 horas. Após este período foram pesadas em balança analítica com precisão de $0,001 \mathrm{~g}$ e os resultados expressos em g/plântula. Ao final todos os dados foram dispostos em tabelas e submetidos à análise estatística.

\section{Resultados e Discussões}

De acordo com a Figura 1 onde estão representados os dados da germinação das sementes de $R$. communis e primeira contagem, observou-se pelo comportamento da linha de tendência que TM2 representa maior percentual de germinação em relação a TM1, e a adição de água acima de duas vezes o peso do substrato afeta negativamente o processo germinativo, característica esta que se inverte quando da adição de 2,5 vezes o volume de água no substrato, onde a partir deste ponto a linha que representa as sementes menores (TM1) ganha características crescentes. Em relação à primeira contagem a distância entre os dois polinômios é ainda mais acentuada, o que indica valor percentual mais baixo de germinação em sementes menores e quando submetidas à substrato com menores volumes de água para umedecimento. 

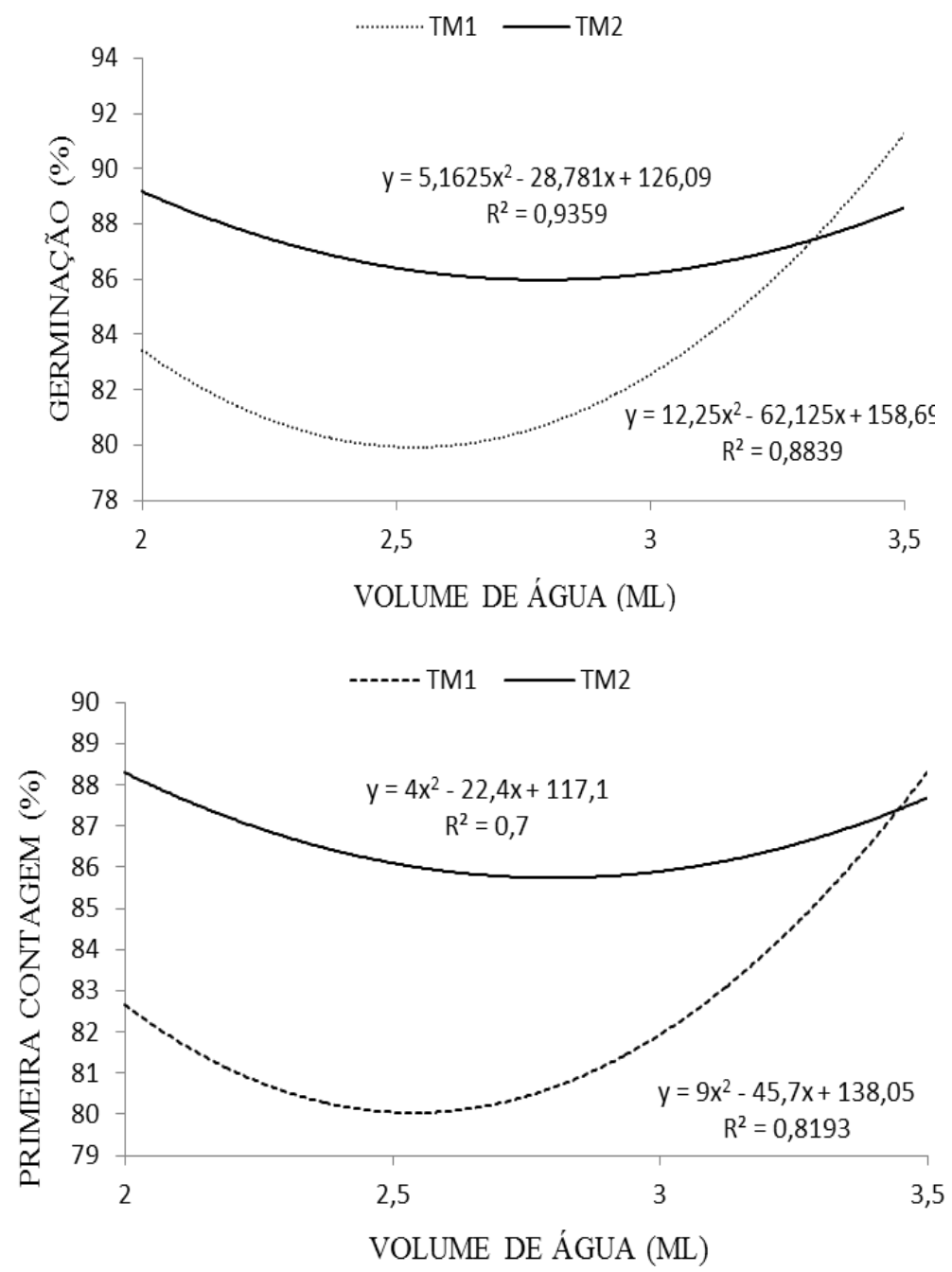

FIGURA 1 Dados da Germinação (\%) e primeira contagem (\%) de sementes de $R$. communis em função de diferentes tamanhos e volumes de água no substrato. TM1- sementes até 10,9 mm e TM2- sementes maiores que 14,0 mm.

O índice de velocidade de Germinação (IVG) representado na Figura 2, mantém a superioridade das sementes de maior tamanho apresentando valores acima e uma tendência decrescente com o aumento do volume de água no substrato, o que se inverte em relação às sementes menores, ocorrendo uma representação exponencial da linha de tendência a partir do umedecimento com 2,5 vezes o peso do substrato.

Ainda na Figura 2 estão representados os dados da massa seca das plântulas de $R$. communis, cujas sementes classificadas em TM1 apresentam maior acúmulo de massa seca com tendência decrescente a partir do umedecimento com 3 vezes o volume de água no substrato. $\mathrm{O}$ mesmo acontece para as sementes maiores que $14 \mathrm{~mm}$, que embora tenham apresentado maiores valores de germinação e primeira contagem não obtiveram um desenvolvimento proporcional. 

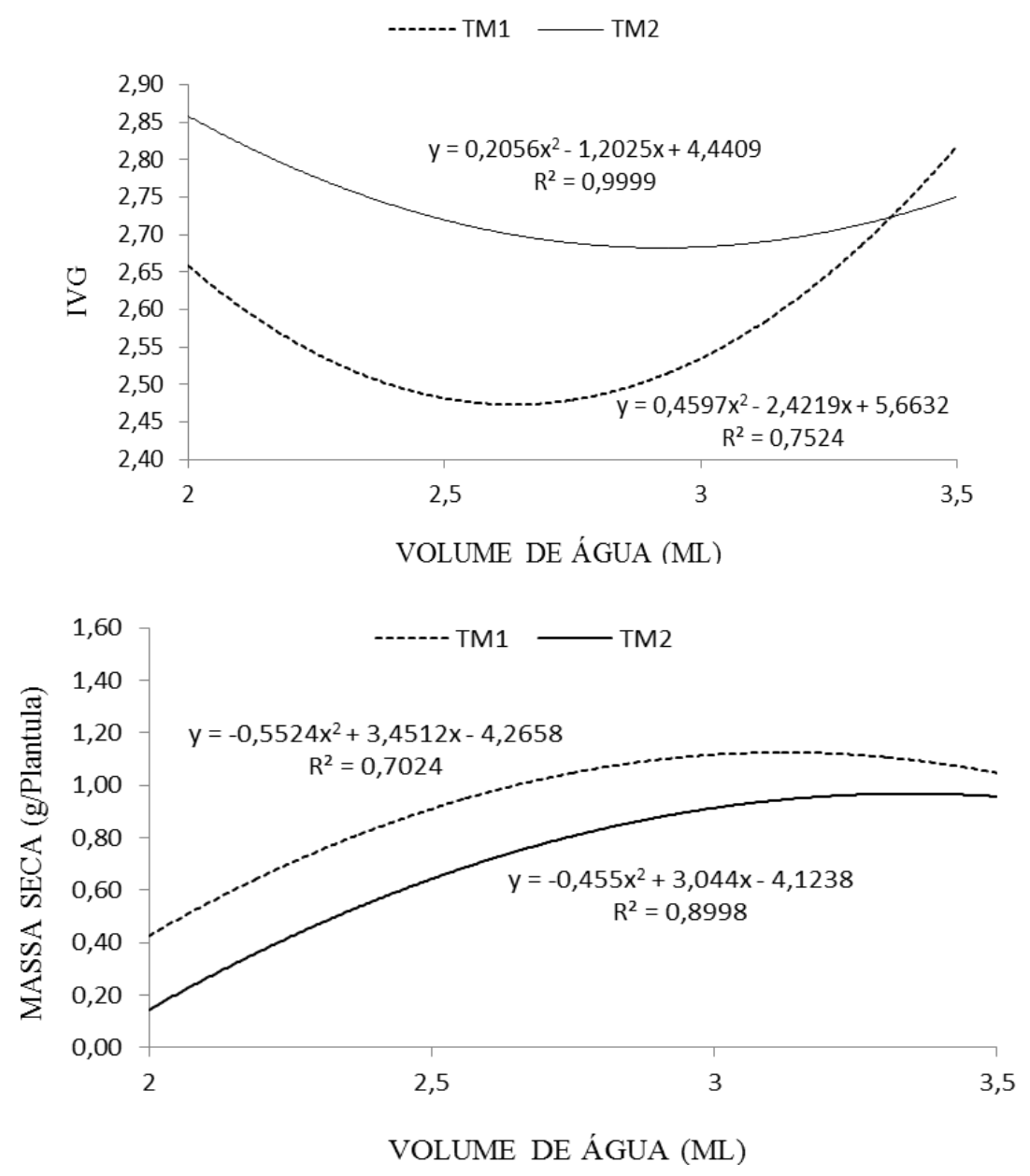

FIGURA 2 Dados do IVG e Massa Seca de sementes de $R$. communis em função de diferentes tamanhos e volumes de água no substrato. TM1- sementes até 10,9 mm e TM2sementes maiores que $14,0 \mathrm{~mm}$.

\section{Conclusões}

Sementes de $R$ communis cultivar BRS Energia maiores que $14 \mathrm{~mm}$ apresentam maior percentual de germinação e maior crescimento quando submetidas até 3 vezes o peso do substrato.

Sementes de $R$ communis cultivar BRS Energia de até $10,9 \mathrm{~mm}$ de tamanho apresentam maior percentual de germinação e vigor quando submetidas à umedecimento do substrato com 3,5 vezes o peso do substrato seco.

\section{Referências}

BIZINOTO, T. K. M. C., OLIVEIRA, E. D., MARTINS, S. B., SOUZA, S. D., \& GOTARDO, M. (2010). Cultivo da mamoneira influenciada por diferentes populações de plantas. Bragantia, 69(2), 367-370. 
CANGEMI, M.J., DOS SANTOS, M.A., \& CLARO NETO, S. (2010). A Revolução Verde da Mamona.

CARVALHO, N.M.; NAKAGAWA, J. Sementes: ciência, tecnologia e produção. 4.Ed. Jaboticabal: FUNEP, 2000, 588p.

FRANÇA, P.R.C.; SILVA, O.R.R.F.; ALMEIDA, F.A.C. (2016). Inovação Tecnológica para Beneficiamento de Mamona: uma alternativa para descascamento dos frutos. Saarbrücken: Novas Edições Acadêmicas. 90 p.

GASPAR, C. M., \& NAKAGAWA, J. (2002). Influência do tamanho na germinação e no vigor de sementes de milheto (Pennisetum americanum (L.) Leeke). Revista Brasileira de Sementes, 339344.

ZUCHI, J., PANOZZO, L. E., HEBERLE, E., \& ARAUJO, E. F. (2012). Curva de embebição e condutividade elétrica de sementes de mamona classificadas por tamanho. Revista Brasileira de Sementes, 34(3), 504-509. 